\title{
THE ARTERIAL MIGRATION OF TROPHOBLAST IN THE UTERUS OF THE GOLDEN HAMSTER, MESOCRICETUS AURATUS
}

\author{
R. PIJNENBORG, W. B. ROBERTSON* AND I. BROSENS \\ Laboratory for Gynaecological Physiopathology, Academisch Ziekenhuis, \\ St Rafaël, Catholic University of Leuven, Belgium
}

(Received 13th September 1973)

Summary. Fifty pregnant golden hamsters, twenty of which were unilaterally pregnant and had deciduomata induced in the sterilized horn, were studied. Conceptuses, without the fetus, and deciduomata were examined histologically from Day 7 to term, Day 16. Special attention was directed towards trophoblast arterial migrations, structural changes in maternal vessels before and during trophoblast migration, and the interaction between trophoblast and maternal vascular tissue. Changes occurred in the maternal vessels during pregnancy which were independent of trophoblast influence; they included the formation of stromal sheaths that became decidualized and were accompanied by intramural stromal granulocyte proliferation. These changes were identical in time and sequence in a conceptus and a deciduoma and were probably mediated by the altered hormonal and haemodynamic status of pregnancy. In a conceptus, there were two separate waves of retrograde arterial trophoblast migration, the first by way of the circumferential system between Days 8 and 12 to the mesometrial triangle, and the second from Day 12 onwards by way of the central spiral arteries and the medial terminal arteries. The first circumferential migration provoked an inflammatory cellular response in the mesometrial triangle whereas the second migration resulted in the transformation of the central arterial supply, as far as the medial terminal arteries, to a series of distended fibrinoid tubes. In the absence of trophoblast, the central arterial supply in deciduomata underwent spontaneous necrosis at the time when the central trophoblast migration was taking place in the conceptus. The results are discussed in relation to the alterations in hormonal status and haemodynamics consequent upon pregnancy and the reaction of trophoblast with maternal blood vessels in relation to possible local hormonal influences and immunological reactions. The general conclusion is that hamster pregnancy, under properly controlled experimental conditions, is a useful model for the study of fundamental mechanisms in haemochorial placentation.

\footnotetext{
* Present address: St George's Hospital Medical School, London.
} 


\section{INTRODUCTION}

The mechanisms which produce a haemochorial type of placentation are far from clear. In women, it is generally accepted that cytotrophoblast is responsible for opening up the maternal blood vessels in the placental bed (Hamilton \& Boyd, 1960; Harris \& Ramsey, 1966; Brosens, Robertson \& Dixon, 1967) but how this is done is still unknown. Rodent placentation has features in common with human placentation and, in particular, hamster placentation with its precisely timed trophoblast arterial migrations (Ward Orsini, 1954; Billington, 1966) mimics the vascular interaction with trophoblast seen in the human placental bed (Brosens et al., 1967). If due caution is observed in extrapolating the interpretation of events from one species to another, the hamster might serve as a useful experimental model for investigation of some fundamental aspects of human placentation. It follows that it is necessary to have an exact knowledge of the sequence of morphological changes that occur in the blood vessels of the uterus in hamster pregnancy. The meticulous studies of the hamster conceptus by Ward Orsini $(1948,1954,1957,1968)$ were largely concerned with the trophoblast, less with the detailed changes in the maternal vessels, and least with the reaction of the one upon the other. The purpose of this communication is to describe the pregnancy-induced changes in the blood vessels of the hamster uterus, the relation of these changes to the characteristic trophoblast migrations, and the interaction of the trophoblast with the blood vessels in particular and the maternal uterine tissues in general.

Since we were not concerned with implantation and the early stages of placentation, which have been described by others (Graves, 1945; Ward, 1948; Ward Orsini, 1954), our account is of the changes from Day 7 to Day 16 with particular reference to the maternal blood vessels.

\section{MATERIALS AND METHODS}

Fifty young female virgin golden hamsters (Mesocricetus auratus) were kept in separate cages under controlled environmental conditions. The animals were maintained on a 16-hr light/8-hr dark schedule (lights on from 06.00 to 22.00 hours) and the temperature was held between 20 and $24^{\circ} \mathrm{C}$. The oestrous cycle of each animal was determined by examination of vaginal smears and on the evening of oestrus the females were caged with males. If spermatozoa were noted in the vaginal smears the following morning, that day was designated Day 1 of pregnancy.

To produce deciduomata, one horn of the uteri of twenty of the fifty hamsters was sterilized by tubal ligation 2 to 3 weeks before mating and deciduoma formation was induced by oil injections into the sterilized horn (Ward Orsini, 1968) on the 4th day of pregnancy in the contralateral horn.

The animals were killed at 10.00 hours on days chosen to give five specimens at each day of pregnancy from Day 7 to term (Day 16). At least two conceptuses and, in the unilaterally pregnant animals, two deciduomata were excised from each animal with the segment of uterus intact and fixed in Bouin's solution. Subsequent processing was by standard methods and each paraffin-wax block 
was cut into serial sections. Ribbons of sections were stained with haemalum and eosin, the periodic acid-Schiff (PAS) technique, the van Giesen technique and selected sections were also stained with the Tanzer orcein technique for elastin and the phloxine-tartrazine method (Lendrum, 1947).

\section{RESULTS}

\section{Conceptus}

Text-figure 1 shows the maternal arterial blood supply to the fully developed conceptus in diagrammatic form. From the complex system of mesometrial segmental arteries and arcades, two main uterine arterial systems arise.

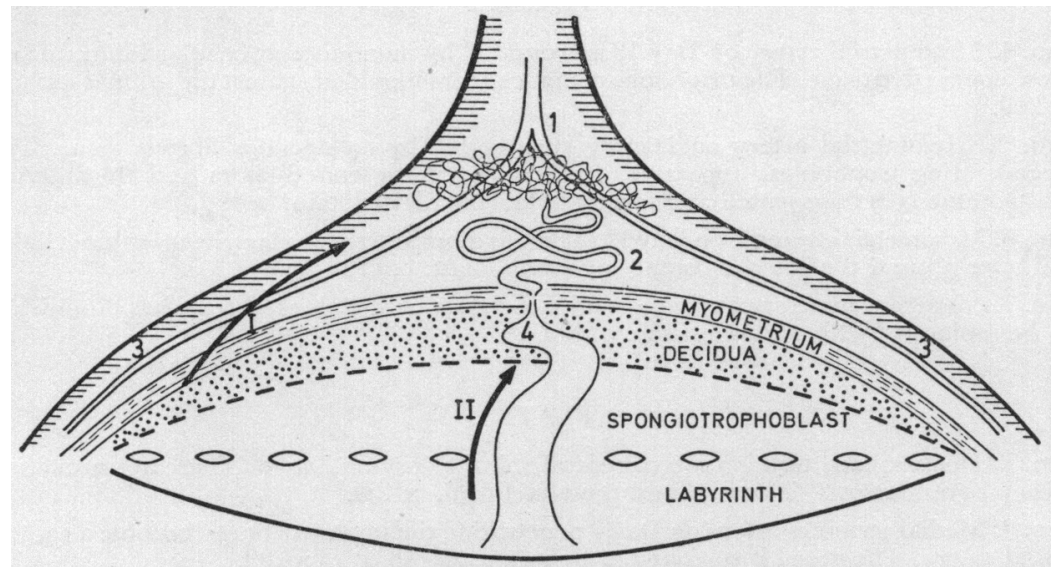

TExT-FIG. 1. Diagram of the arterial supply to the mature hamster placenta. 1, Mesometrial arteries; 2 , medial terminal artery; 3 , circumferential arteries; 4 , central spiral artery.

The first is a number of small medial arteries forming what is called the anastomosing knot. From this knot in the mesometrial triangle, two or three medial terminal arteries take origin and penetrate the myometrium to reach the decidua where they become the central spiral arteries. The maternal segments of the spiral arteries terminate at, and open into, a sinsusoidal system formed by the trophospongium. From about Day 10, probably by haemodynamic influences, channels which are direct extensions of the maternal spiral arteries are driven through the whole thickness of the placenta into the labyrinth to supply maternal blood to fetal tissues. Having perfused the labyrinth, the maternal blood returns through the trophospongium to empty into decidual veins. Although the lining of these intra-placental channels is formed entirely by fetal tissue, the system is called the maternal arterial space.

The second arterial system comprises the circumferential arteries which travel round the uterus between the inner circular and outer longitudinal layers of the myometrium to reach, and anastomose at, the antimesometrial aspect of the uterus. They give off small penetrating branches into the decidua but their rôle in supplying the placental bed is probably a minor one although they may nourish the inverted yolk-sac placenta. 


\section{EXPLANATION OF PLATES 1 TO 5}

All tissues were obtained at autopsy from golden hamsters between Day 7 and Day 16 of pregnancy.

\section{PLATE 1}

Frg. 1. Artery in mesometrial triangle at Day 7 surrounded by loose connective tissue. The medial smooth muscle is swollen and there are globules of acidophilic material in the wall. H \& E. $\times 490$.

FIG. 2. Circumferential artery on Day 7. Swollen media with mitotic figure (arrowed). $\times 780$.

FIG. 3. Stream of trophoblast giant cells in the circumferential arteries on Day $10 . \times 200$.

\section{PLATE 2}

Fig. 4. Mesometrial artery on Day 13 surrounded by mononuclear cellular infiltrate and loose connective tissue. The trophoblast giant cells are moulded against the intimal surface. $\times 200$.

FIG. 5. Mesometrial artery on Day 16 surrounded by collagenous fibrous tissue. The degenerating trophoblast appears to have replaced the endothelium and the internal elastic lamella is fragmented and focally deficient. Elastin stain. $\times 490$.

Fig. 6. Mesometrial triangle on Day 13. There is a brisk perivascular pleomorphic cellular infiltrate around the arteries containing trophoblast. $\times 120$.

Fic. 7. Mesometrial artery on Day 16. The perivascular cellular infiltrate has diminished to be replaced by fibroblastic tissue. $\times 200$.

\section{PLATE 3}

Fig. 8. Decidualized termination of central spiral artery on Day 8. There are numerous stromal granulocytes in and around the vessel wall. $\times 490$.

Fig. 9. Medial terminal artery on Day 7 penetrating the myometrium to become a central spiral artery. The vessel is surrounded by its stromal sheath. $\times 200$.

FIg. 10. Medial terminal artery on Day 9. The endothelium is swollen and the media is being occupied by large, pale, swollen cells resembling decidual cells. $\times 780$.

FIG. 11. Decidualization of the medial terminal artery on Day 11. From this day to term, stromal granulocytes are seen in the wall of the artery at this level, $\times 200$.

\section{PLATE 4}

FIG. 12. Spiral artery on Day 11. The decidualized wall is overwhelmed by stromal granulocytes. $\times 490$.

FIG. 13. Central spiral artery on Day 12. The whole length of the spiral arteries has been invaded by endovascular trophoblast. Note the apocrine appearance of the luminal surfaces and the endometrial granulocytes external to the trophoblast. $\times 200$.

FIG. 14. Central spiral artery on Day 15. The vessel wall has been converted to a fibrinoid tube with trophoblast lining the lumen and embedded in the fibrinoid wall. The stromal granulocytes have almost disappeared. $\times 200$.

\section{PLATE 5}

Frg. 15. Intra-myometrial segment of spiral artery (top, left) on Day 15. Trophoblast can be seen (arrows) escaping through the wall of the vessel to lie free in the myometrium. There is no fibrinoid or other reaction. $\times 200$.

Frg. 16. Arteries in the mesometrial triangle on Day 15. Trophoblast (arrows) can be seen lying free in the loose connective tissue around the vessels; again there is no maternal tissue reaction. $\times 490$.

Fig. 17. Spiral artery of deciduoma on Day 12. Numerous stromal granulocytes in the decidualized wall but no trophoblast is present. $\times 200$.

FIG. 18. Spiral artery of deciduoma on Day 15. Spontaneous necrosis of vessel wall in the presence of numerous stromal granulocytes. $\times 200$. 


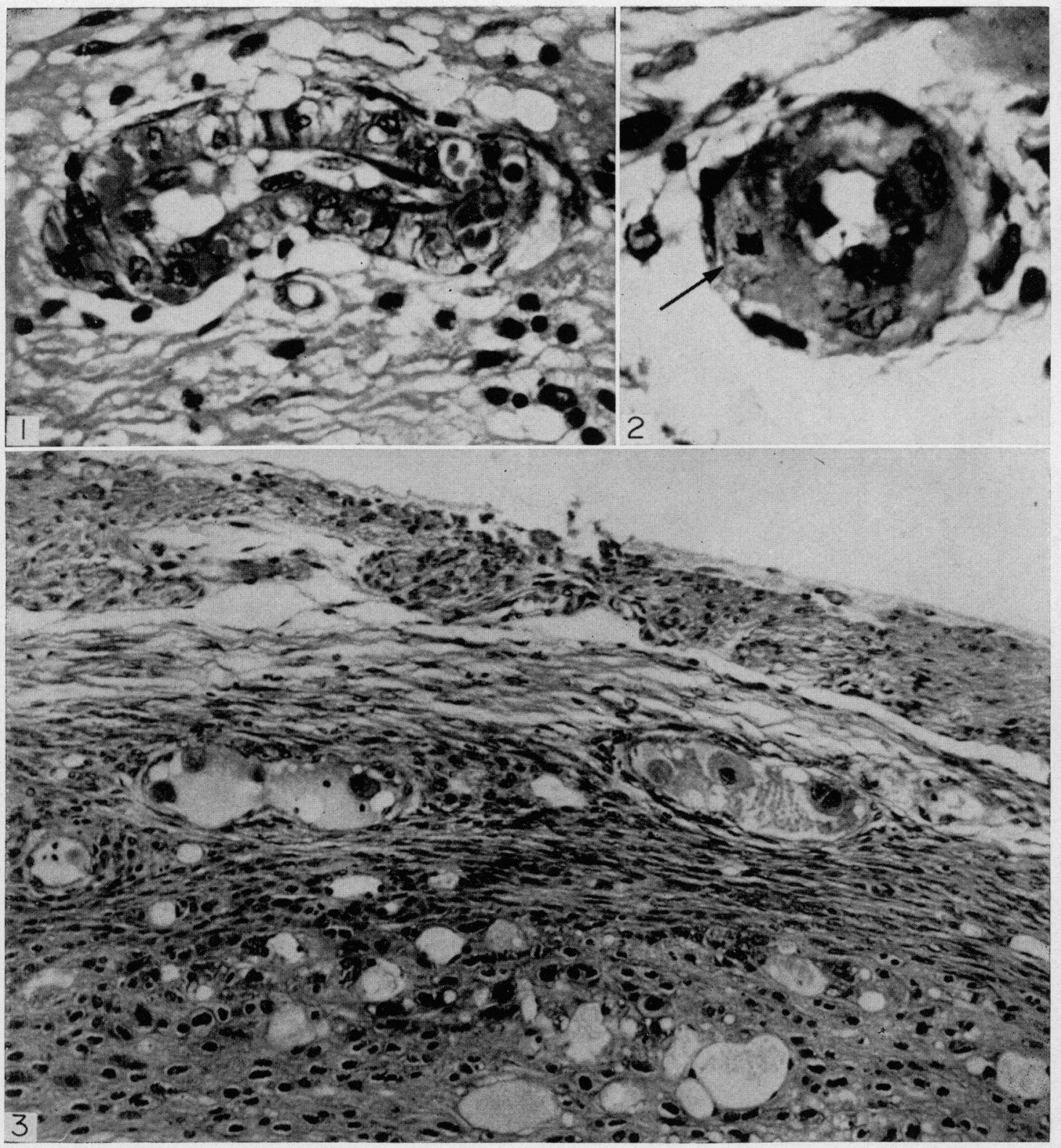

(Facing p. 272) 


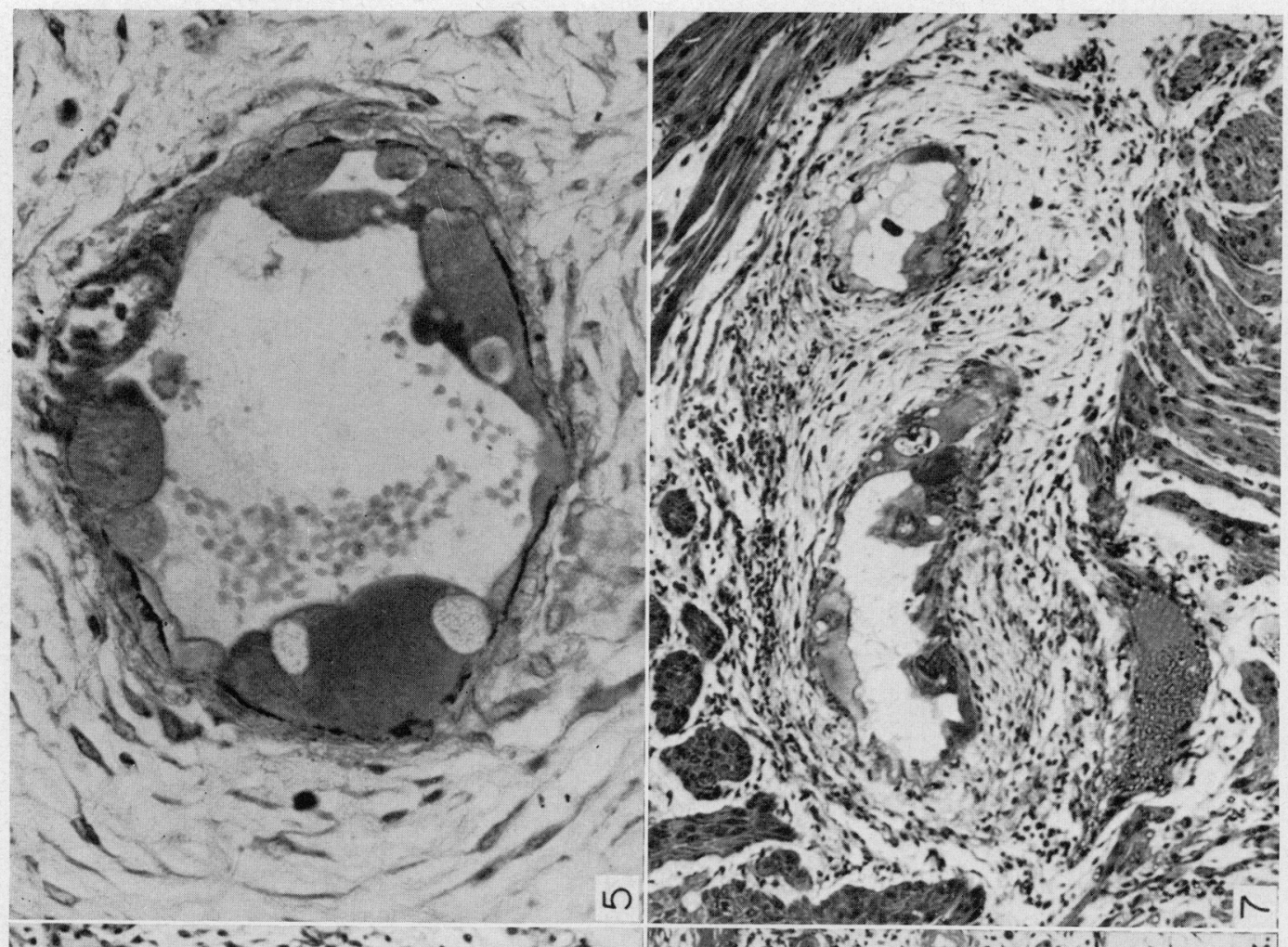

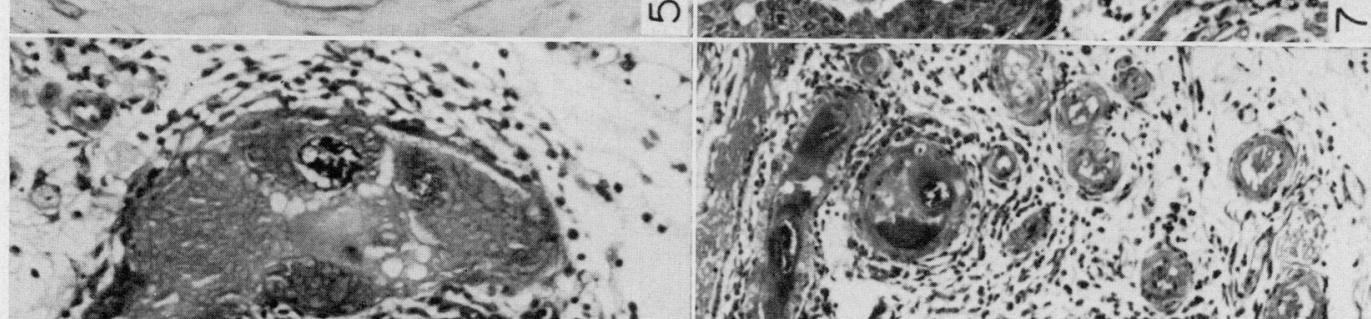

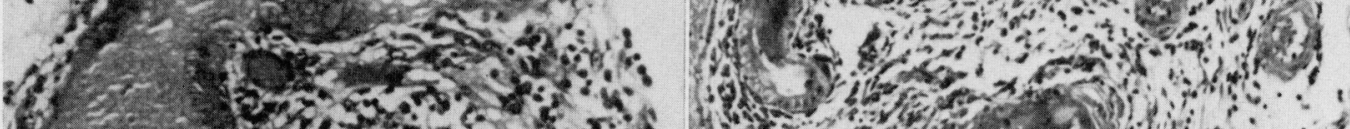

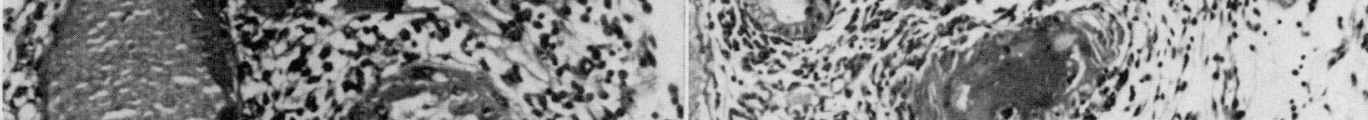

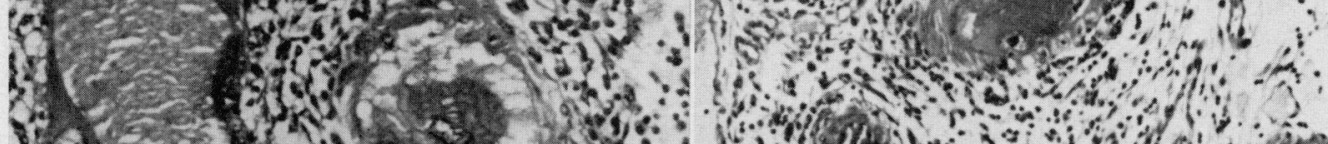

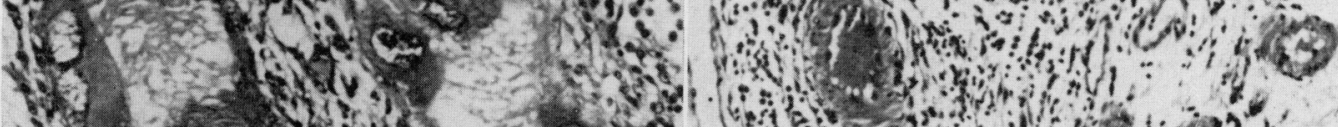

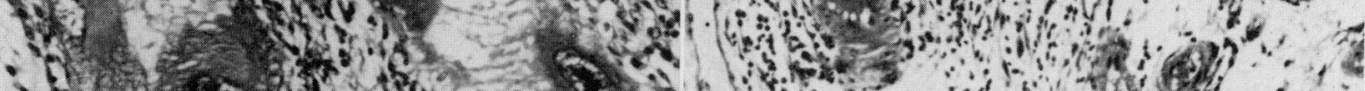

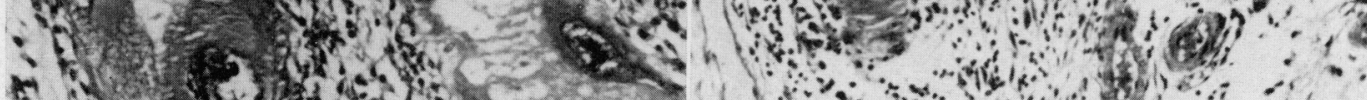

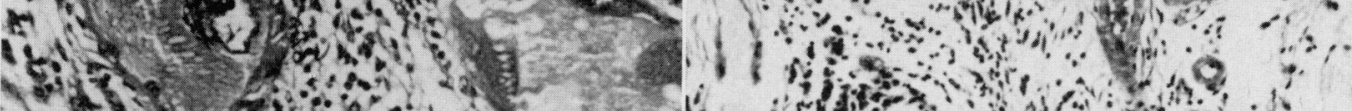

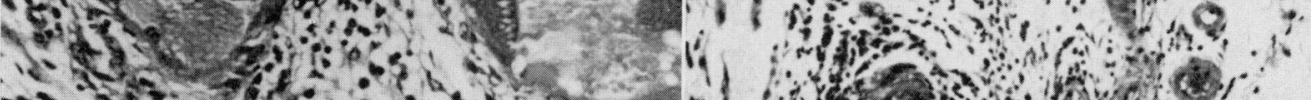

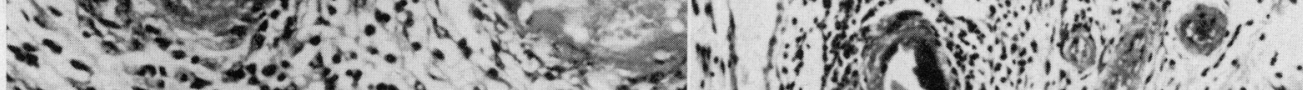

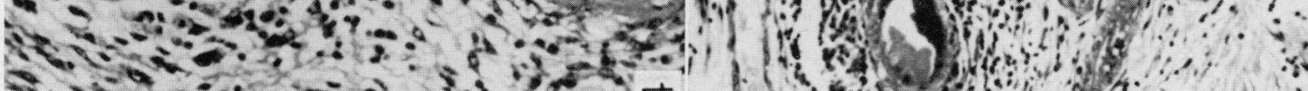

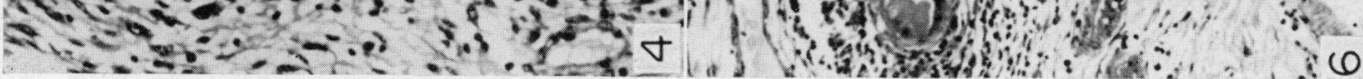




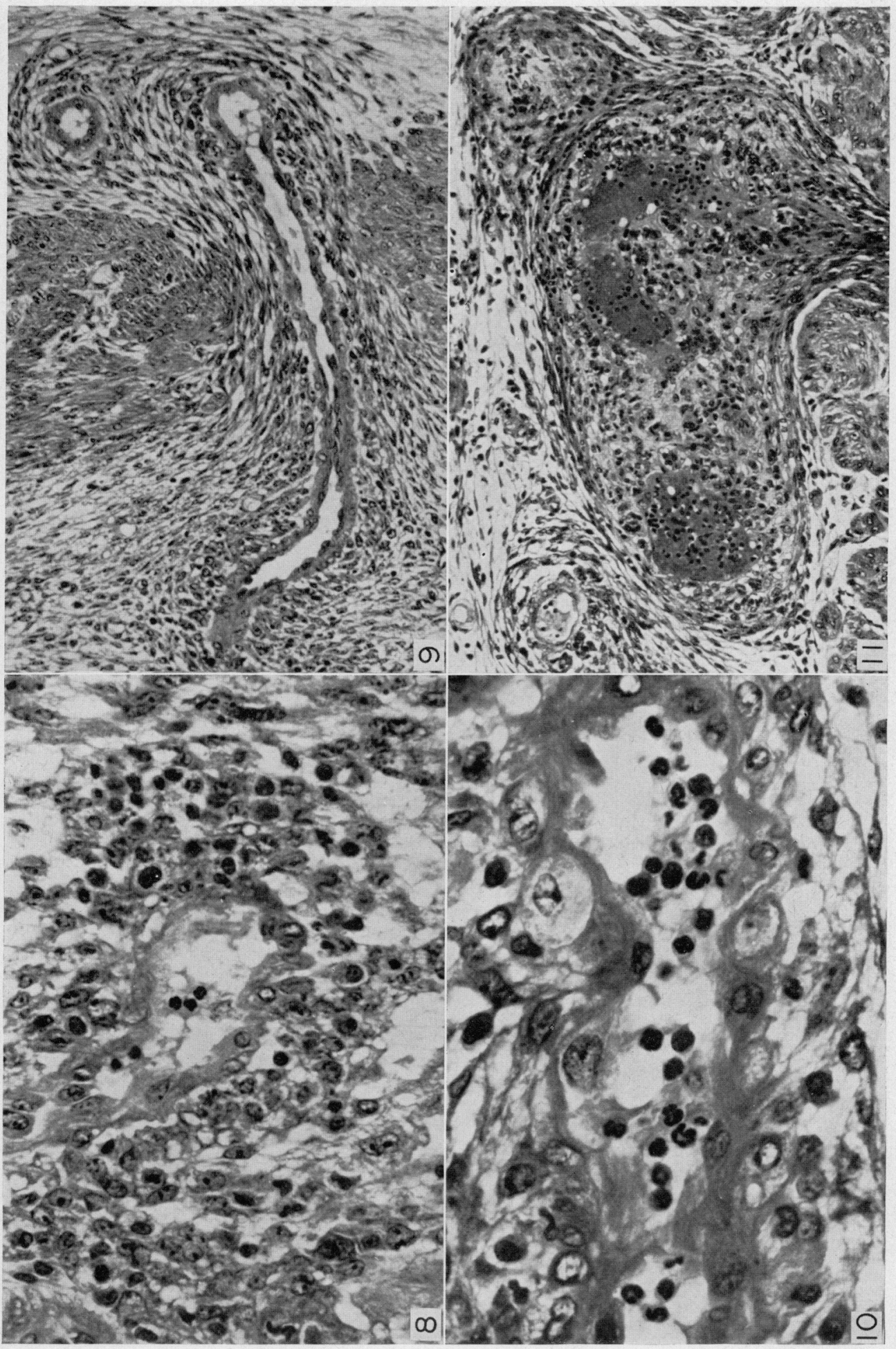




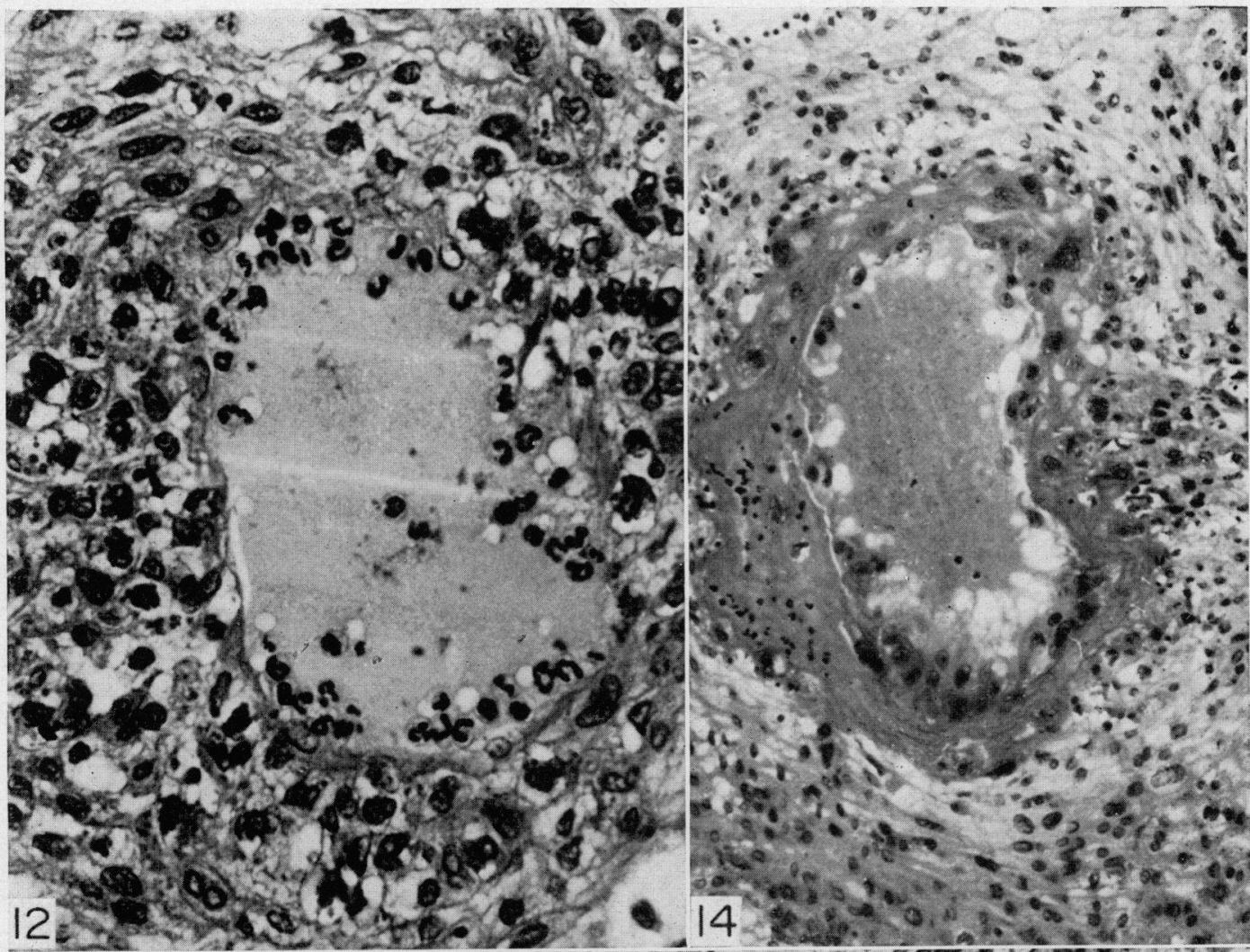

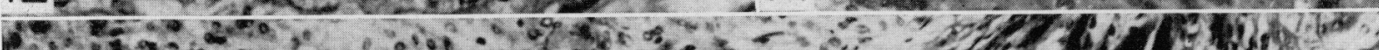

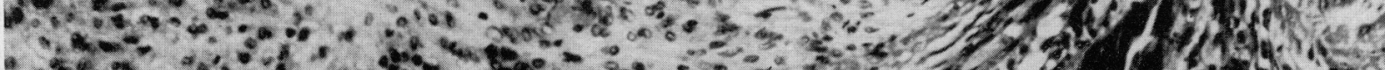
6.

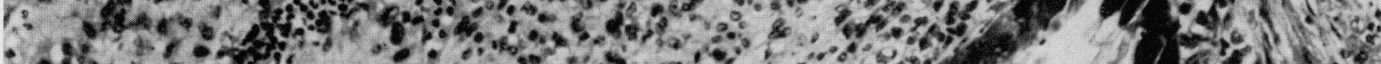

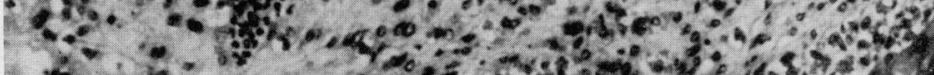

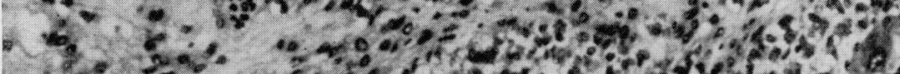

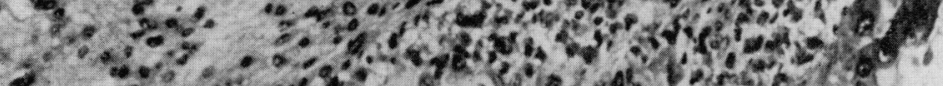
50.

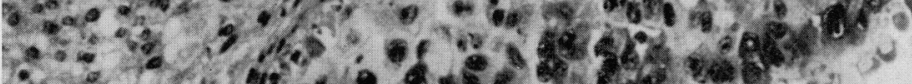

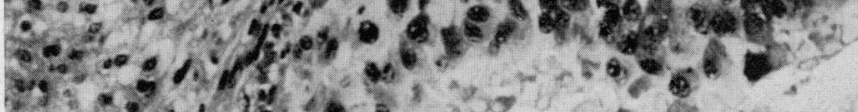
- 4.5. F. 6.

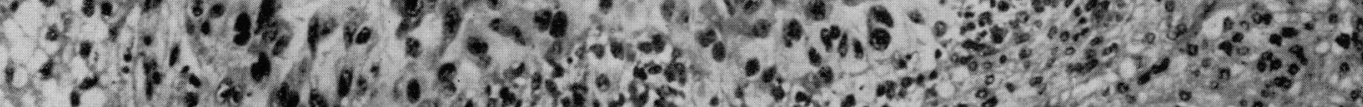

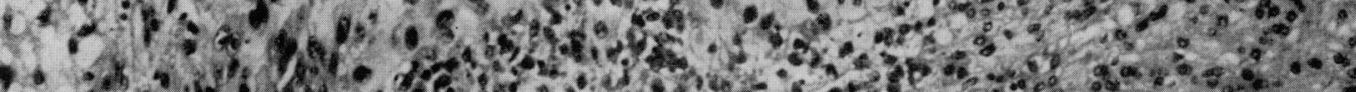

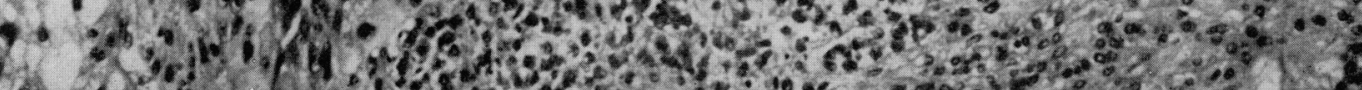

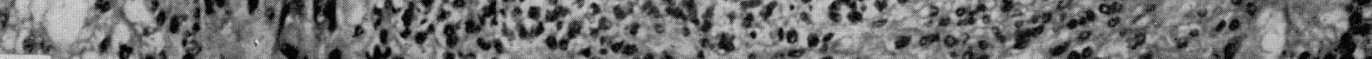
13 a 


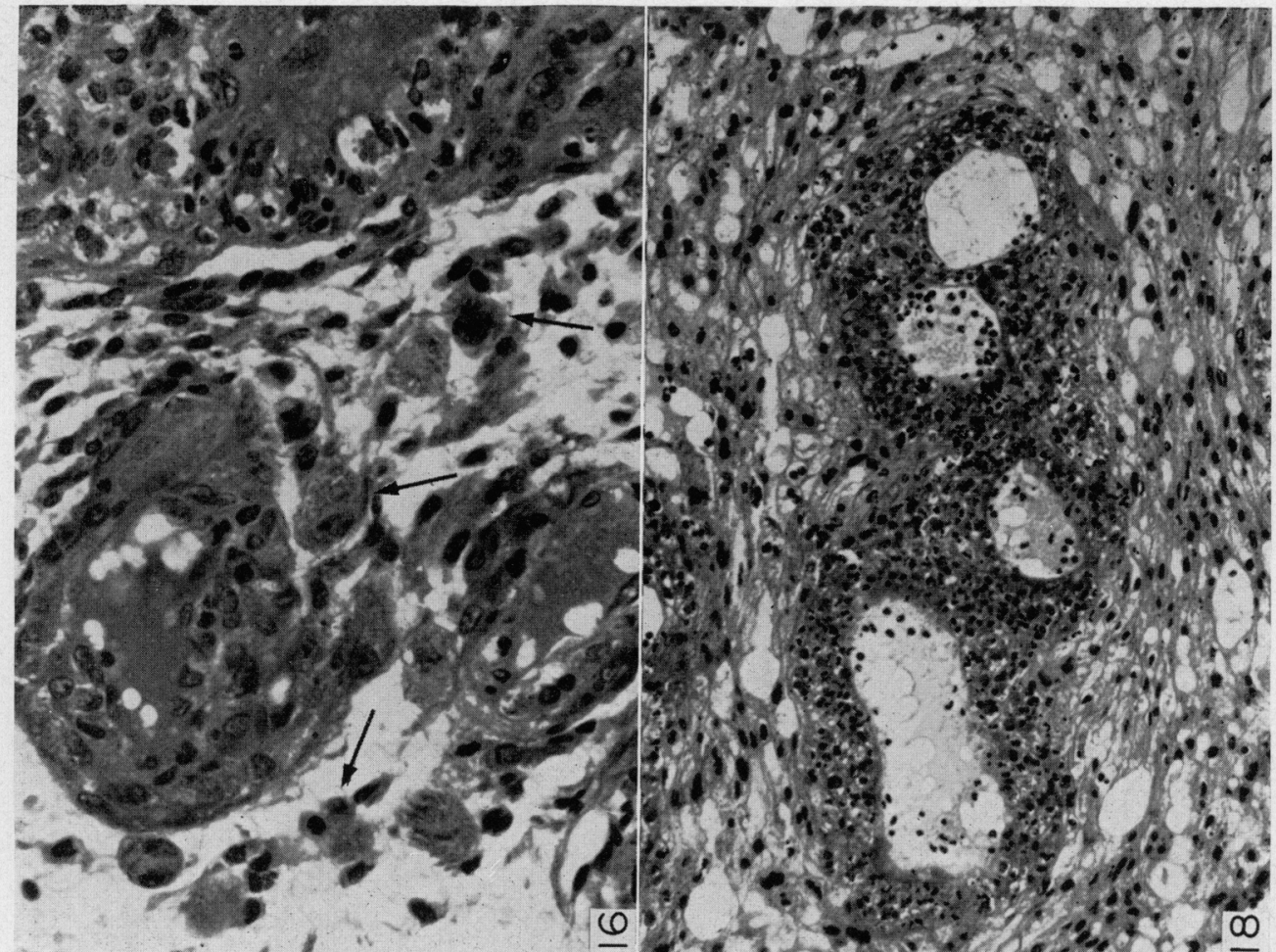

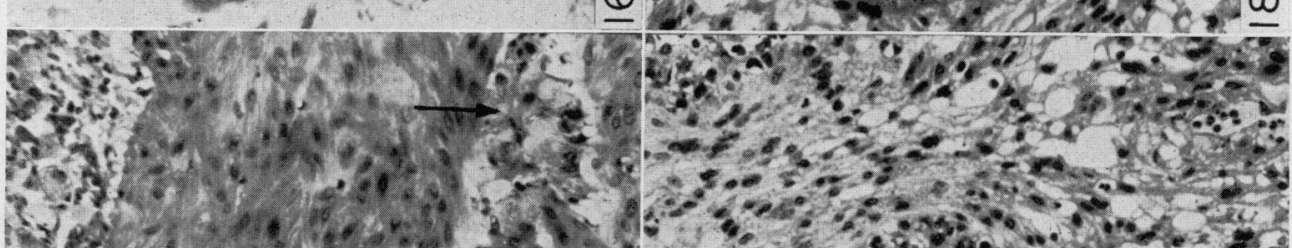

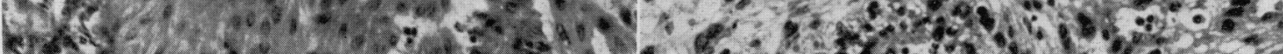
20.

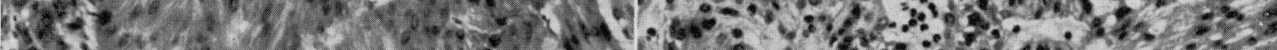
M. 5.5.

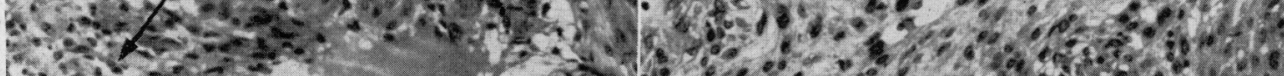

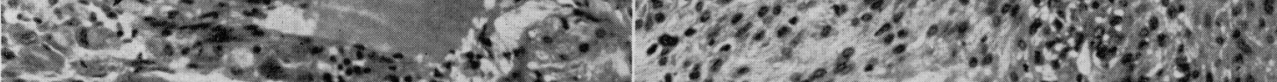

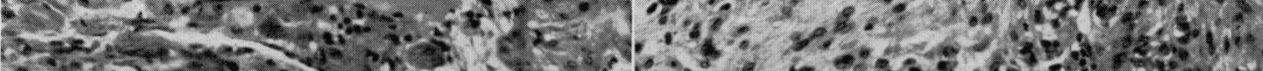

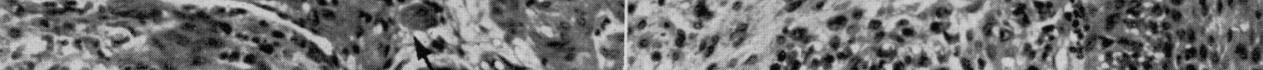
4.

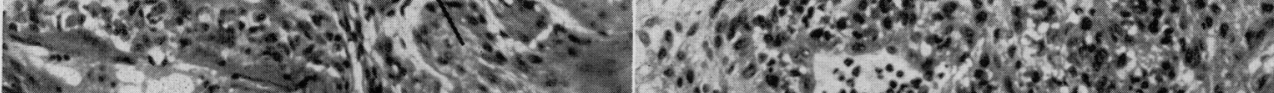

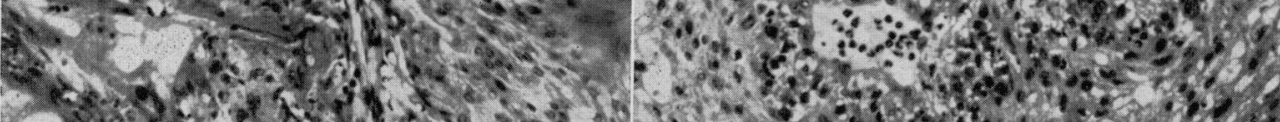

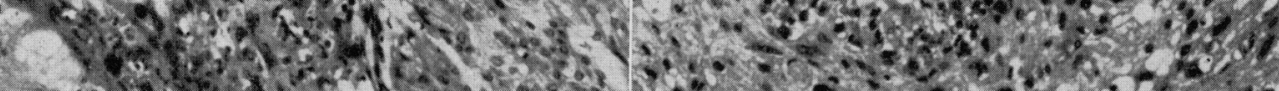

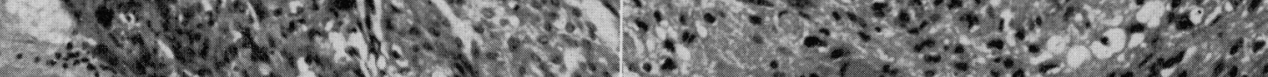

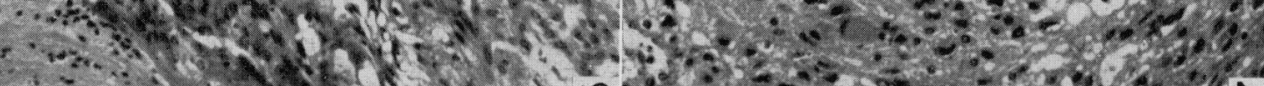

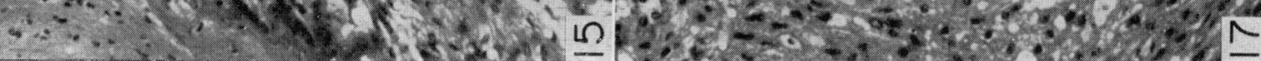


As there are two distinct waves of trophoblast arterial migration, the first by way of the circumferential system and the second by way of the central system, the events in each system will be described separately, followed by the sequence of changes in deciduomata.

By Day 7, before the first trophoblast migration, the mesometrial arteries, the anastomosing knot and the proximal portions of the circumferential arteries show changes in their walls. These changes include accumulation of eosinophilic, PAS-positive material, often in quite large globules, in the groundsubstance of the media, rounding up and vacuolation of the medial smooth muscle cells and occasional mitoses (Pl. 1, Figs 1 and 2). At this stage, there is no perceptible alteration in the vascular elastic tissue. Around these vessels, there is a loose connective tissue stroma. By Day 8 , giant mononuclear trophoblasts from the region of Reichert's membrane gain entry into the decidual terminations of the circumferential arteries on the lateral and antimesometrial aspects of the uterus. They begin to migrate against the blood flow and during Days 10 to 12 streams of such cells can be seen in the main circumferential arteries (Pl. 1, Fig. 3) and also in their ultimate destination, the anastomosing knot and mesometrial arteries. Their passage along the circumferential arteries appears to provoke no reaction but when they reach the mesometrial triangle, they settle there, appear to replace or engulf the endothelium of the arteries and mould themselves against the intima (Pl. 2, Fig. 4). A thin rim of pericellular eosinophilic material usually surrounds individual trophoblasts and changes can be seen in the internal elastic lamina, including fragmentation and apparent dissolution to produce gaps (Pl. 2, Fig. 5). In contrast to the absence of reactive change in the circumferential arteries, there is a brisk periarterial cellular reaction in the mesometrial triangle (PI.2, Fig. 6). The cellular exudate is pleomorphic, being composed of macrophage-type cells and smaller mononuclear cells with occasional plasma cells, mast cells and eosinophil leucocytes. By the end of Day 12, the first migration of trophoblast by way of the circumferential arteries is completed. During the last few days of pregnancy, the pleomorphic cellular exudate in the mesometrial triangle is gradually replaced by cellular fibrous tissue (Pl. 2, Fig. 7).

In the central arterial system, a sequence of somewhat different changes takes place in the walls of the central spiral arteries and their parent medial terminal arteries before the second trophoblast migratory wave. At Days 7 and 8, the terminations of the central spiral arteries where they open into the trophospongium have lost their smooth muscle and appear as terminal arterioles whose walls are entirely composed of decidualized cells (PI. 3, Fig. 8). The proximal segments of the central spiral arteries and the medial terminals meanwhile are invested by stromal cells to form sheathed arteries (Pl. 3, Fig. 9). From Day 9 onwards, the sheathed arteries undergo changes somewhat analogous to those that occurred earlier in the mesometrial arteries and the anastomosing knot with the appearance of large round cells resembling decidual cells in their walls (Pl. 3, Fig. 10). There is then a progressive decidualization of the sheathed arteries from the distal to the proximal segments up to Day 12 (Pl. 3, Fig. 11).

While the sheathed arteries are developing, a new phenomenon is seen in the decidual terminations of these arteries. Early in hamster placentation, a differ- 
ent type of cell appears in the decidua near the trophospongium; this is the stromal granulocyte, a maternal cell of undetermined origin which has a vesicular reniform nucleus and large eosinophilic and phloxinophilic cytoplasmic granules. As decidualization of the central arterial supply progresses, granulocytes appear in the artery walls, often to such an extent that they mask the previously decidualized wall (Pl. 4, Fig. 12). Associated with the decidualization and the presence of the granulocytes, there are deposits of large quantities of PAS-positive material, probably glycogen and possibly protein-polysaccharide complexes in the medial ground-substance. It is at this stage that the second migration of trophoblast occurs by way of the central arterial supply.

From Day 8 to Day 12, the decidualized terminations of the spiral arteries in the basal layer adjacent to the trophospongium gradually become plugged with trophoblast. In the early stages of this invasion of the maternal vascular system, the trophoblast is actively phagocytic for the accumulations of leucocytes in the lumina of the vessels. Precisely at Day 12, the trophoblast begins to migrate up the now decidualized wall of the central spiral artery and striking changes in the trophoblast and the artery wall ensue. The luminal surface of the trophoblast, which appears to have replaced the endothelium, becomes intensely eosinophilic and vacuolated with a cap-like appearance resembling an apocrine-type secretion (Pl. 4, Fig. 13). The basal aspect of the cells is basiphilic, probably due to concentration of the cytoplasmic RNA. The colonization of the artery wall is accompanied by the production of much fibrinoid material and almost total loss of the decidualized media with its complement of granulocytes. The net result is the conversion of the maternal blood vessel to a fibrinoid tube containing trophoblast (Pl. 4, Fig. 14). The conversion of the central spiral arteries to fibrinoid tubes ultimately extends retrogradely into the medial terminal arteries adjacent to the myometrium but not beyond. No such changes were seen in the arteries of the mesometrial triangle as a consequence of the first trophoblast migration.

When this second trophoblast migration reaches the medial terminal arteries where they penetrate the myometrium, migration occurs from the vessels into the myometrium itself and here, in striking contrast to the situation in the vessel wall, there is no fibrinoid reaction in the myometrium (Pl. 5, Fig. 15). By Day 14, the trophoblast has reached the anastomosing knot where further escape of the trophoblast into the connective tissues of the mesometrial triangle occurs and once again there is little reaction to its presence with a conspicuous absence of fibrinoid production (Pl. 5, Fig. 16).

In the last days of pregnancy (Days 14 to 16), the central arterial supply as far as the medial terminal arteries undergoes a progressive distension due to the accumulation of fibrinoid tissue and loss of the original arterial wall.

\section{Deciduomata}

Since it is difficult to separate the part played by intrinsic alterations in the maternal vascular system from the action of migrating trophoblast in the sequence of events in the placental bed, the vascular changes in deciduomata of unilaterally pregnant animals were studied in exactly the same way as in conceptuses. The intrinsic vascular changes in a deciduoma exactly paralleled, 
in time and sequence, those in a conceptus, including the development of a sheathed central arterial supply with subsequent decidualization and the appearance of granulocytes (Pl. 5, Fig. 17). During Days 8 to 12, just as in the normal placental bed, there was a leucocytosis in the lumina of the central

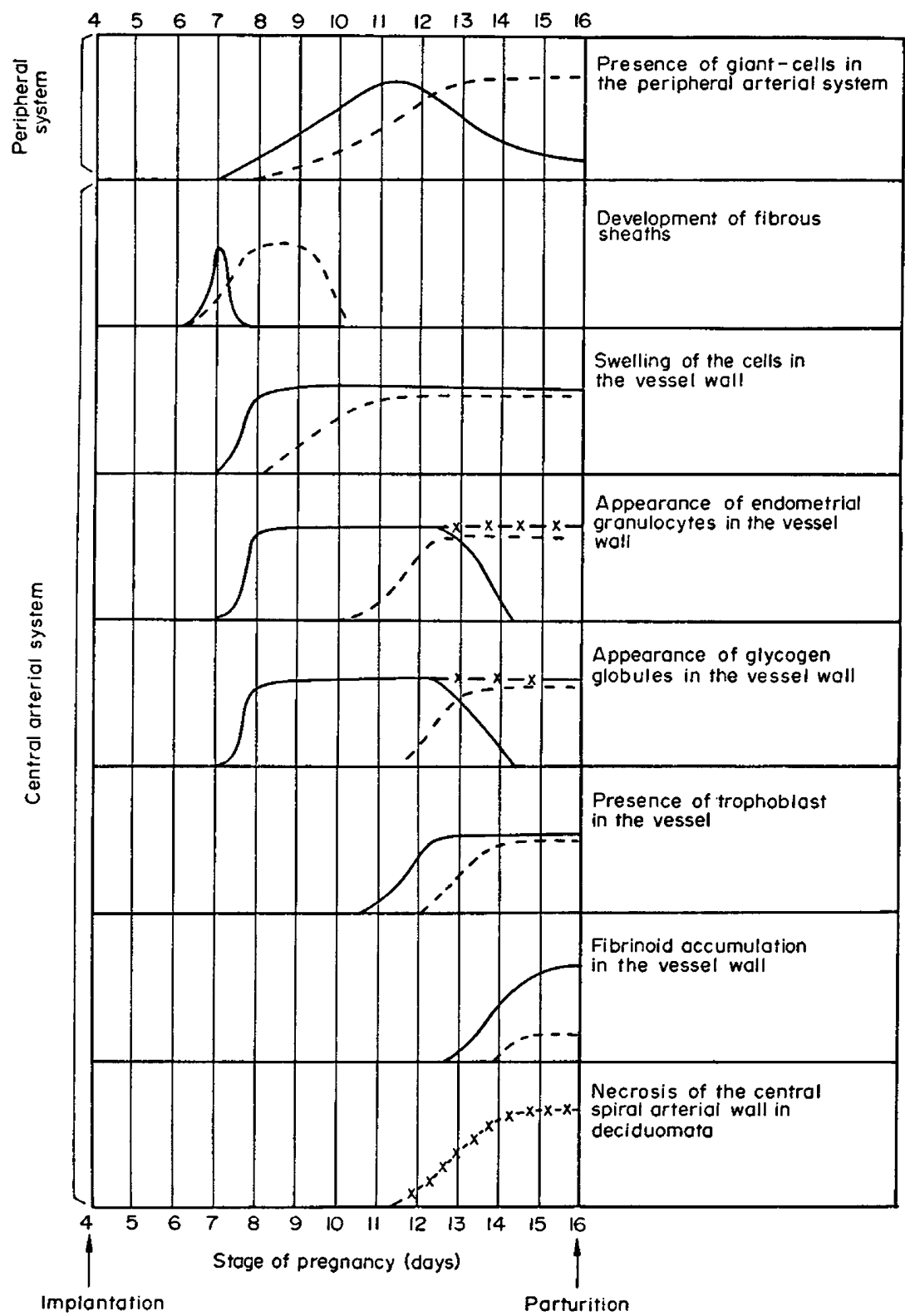

TExT-FIG. 2. Time relationships of morphological events in the hamster placental bed and deciduoma. The day of gestation can be determined precisely from these graphs. In the peripheral system (top) solid line (-) represents the circumferential artery and the broken line (- - ) represents the mesometrial artery. In the central arterial system (lower diagrams), $\left(\frac{}{)}\right)$ represents the central spiral artery, $(--)$ the medial terminal artery, and $(x-x)$ the spiral artery of a deciduoma. 
arterial supply. In the absence of trophoblast, however, there was no perivascular cellular reaction in the mesometrial triangle at the time that the first circumferential trophoblast migration would have occurred, nor was there fibrinoid change in the central arterial supply at the time the second migration would have taken place. From Day 13 onwards, there was spontaneous necrosis, perhaps associated with the action of stromal granulocytes, in the decidual spiral arteries (Pl. 5, Fig. 18) spreading retrogradely ultimately to reach the medial terminal arteries but not beyond them.

Text-figure 2 summarizes and collates this sequence of events showing the time relationships, by days, of vascular changes and trophoblast migrations in uterine horns containing conceptuses and vascular changes in horns containing only deciduomata.

\section{DISGUSSION}

The earliest reference to endovascular trophoblast in the hamster would appear to be that of Droogleever Fortuyn (1929) who, in a study of prenatal death in the striped hamster (Cricetulus griseus), concluded, mistakenly we think, that trophoblast giant cells in large numbers in the mesometrial arteries were indicative of intrauterine death. Graves (1945) noted the migration of trophoblastic giant cells away from Reichert's membrane in the early stages of embryonic development. Adams \& Hillemann (1950) first described the development of the mature placenta in the hamster but, in confusing trophospongium with 'uterine stroma', they missed entirely the vascular migration of the trophoblast.

The credit for working out many of the details of trophoblast migration in hamster placentation must go to Ward Orsini $(1948,1954,1957,1968)$ whose series of careful studies has become the standard treatise. Our findings regarding the anatomy of the vascular supply to the pregnant uterus agree with hers but we cannot agree with her (1957) assertion that "The stimulus for development of a vascular knot is certainly the development of its associated placenta" and she noted subsequently (1968) that sheathed arteries and a vascular knot develop in relation to deciduomata in unilaterally pregnant animals. We agree that the adaptation of the vascular anatomy of the uterus would appear to be related to the formation of decidual tissue and to the general status of pregnancy and pseudopregnancy and is not dependent upon the presence of fetal tissue in the uterine segments.

The changes in the walls of the mesometrial and proximal circumferential arteries before the first migration of trophoblast include deposition of glycogen and probably alterations in the protein-polysaccharide complexes of the groundsubstance of the arterial wall. Since these changes are seen in relation to a conceptus, a deciduoma and also in parts of the pregnant uterus unassociated with either, it must be presumed that they are mediated by the altered hormonal status of pregnancy. It has been suggested that a similar situation may exist in the human pregnant uterus (Robertson \& Manning, 1974).

The next prominent change seen in the central arterial supply, the development of vascular sheaths from the mesenchymal stroma, still eludes a satis- 
factory explanation but clearly depends upon maternal and not fetal factors since sheathed arteries are common to the placental bed and to deciduomata. Again the altered hormonal status of pregnancy is presumed to be largely responsible, uterine tissues being composed of target cells for steroid hormones, particularly oestrogen and progesterone. We would suggest that the high progesterone levels are mainly responsible for what we have termed decidualization of the central arterial supply, as it is generally accepted that one of the major actions of progesterone is the conversion of oestrogen-primed endometrial stroma to decidua. Whether the decidua-like cells seen in the media of the central arterial supply are transformed smooth muscle cells or infiltrating decidualized stromal cells remains to be determined. Ward Orsini (1954) seems to consider that the stromal cells of the sheaths are transformed to stromal (metrial) granulocytes as a specialized form of decidual cell. We agree with this interpretation but the possibility remains that the stromal granulocytes could migrate into the artery wall from the surrounding decidua where they are first seen.

The stromal granulocyte is a prominent cell in many species with haemochorial placentation. Only a few people (Hamperl, 1954; Hellweg, 1957; Hellweg \& Shaka, 1959; Dallenbach \& Dallenbach-Hellweg, 1964; Jaeger \& Dallenbach-Hellweg, 1969) have studied this cell in the human and its possible rôle in placentation, but it has been studied extensively in the rat as the 'metrial cell'. Various functions have been attributed to this cell; nutrition of the embryo and hormone secretion (Selye \& McKeown, 1935), relaxin production (Dallenbach-Hellweg, Battista \& Dallenbach, 1965) and holocrine secretory activity to disrupt the muscle coats during expansion of the pregnant uterus (Bloch, 1964). Theories of the cell's origin are equally diverse; from connective tissue or smooth muscle cells (Selye \& McKeown, 1935), from endometrial stromal cells (Dallenbach-Hellweg t al., 1965), and from lymphoid tissue (Smith, 1966). A recent study (Larkin \& Schultz, 1968), using autoradiographic techniques, supports the idea that they derive from the local connective tissue elements. Electron-microscopy (Peach \& Bulmer, 1965) provides evidence that the granules are lysosomal in nature. In the hamster, the presence of stromal granulocytes in the walls of the central arterial supply in the placental bed and in the corresponding vessels undergoing necrosis in deciduomata suggests a lytic function for these cells and it may be that the leucocytosis seen in these vessels is a response to the granulocyte activity. Ward Orsini (1968) commented on the central necrosis that eventually occurs in deciduomata but did not relate this to the vascular changes.

We disagree with Ward Orsini (1954) concerning the routes followed by the two separate trophoblast migrations. We are convinced that the first migration travels by the circumferential arteries to reach the mesometrial triangle although we would not exclude the possibility of a few cells at this time (Days 7 to 12) negotiating the narrow intramyometrial segment of the central spiral artery. While Ward Orsini noted trophoblast in the circumferential arteries, she evidently thought that its appearance was due to centrifugal migration from the placental bed or from the arteries in the mesometrial triangle which she considered were populated through the central supply. We were impressed with the 
degenerate appearance of trophoblast in the terminal branches of the spiral arteries at this stage in contrast to the obvious viability of similar cells in the circumferential arteries and in the arteries of the mesometrial triangle. Ward Orsini's classification of trophoblastic cells into three types of giant cells, plus a fourth category of endovascular cells, seems unnecessarily refined. The primary giant cells are derived from the trophoblast at the periphery of the blastocyst excluding the area where the ectoplacental cone will develop. Later, some of these giant cells migrate away from Reichert's membrane through the circumferential arterial system and there is no need to classify them separately as tertiary giant cells. The ectoplacental cone takes part in the formation of the labyrinth and gives origin to the whole of the trophospongium. From the trophospongium, the secondary giant cells are formed and also the endovascular cells which probably arise from small, more primitive trophoblast at the base of the trophospongium. We would therefore suggest that only two categories of trophoblastic cells need be recognized, one from the non-conal area of the blastocyst and the other from the ectoplacental cone. The morphology of all these cells is probably determined more by local environmental conditions than by any intrinsic differences in the cell types.

Rather surprisingly, Ward Orsini makes only fleeting reference to the nature of the pronounced changes that occur in the maternal vessels as a result of interaction with the migrating trophoblast, although Billington (1966) clearly interprets her findings to imply such changes. There is no mention of the striking perivascular cellular response in the mesometrial triangle associated with the first trophoblast migration, nor of its gradual replacement by fibrous tissue which becomes the sclerotic tissue (Ward Orsini, 1954) around these vessels after parturition. She noted degeneration of the central spiral artery walls and the replacement by layers of "endovascular cells" with "hyaline strands" between the cells but this hardly describes the remarkable fibrinoid reaction between the migrating trophoblast and the maternal artery which appears to be of fundamental importance in haemochorial placentation. Here there is a very close analogy with the situation in human pregnancy where the colonization by trophoblast of the spiral arteries of the placental bed is accompanied by fibrinoid deposition in the walls of the arteries (Brosens et al., 1967). De Wolf, De Wolf-Peeters \& Brosens (1973) have shown by electronmicroscopy that much of this human vascular fibrinoid is secreted by the trophoblasts as microfibrillary material but it also has a component of maternal fibrin. The appearance of the trophoblast in the central spiral arteries of the hamster placental bed is certainly in keeping with protein secretion but evidence from other techniques will be required to assess the degree of fetal or maternal origin.

The unexplained absence of a fibrinoid reaction in the walls of vessels in the mesometrial triangle at the time of the first trophoblast migration, and the lack of a reaction to the trophoblast which escapes from the medial terminal arteries into the myometrium and connective tissues in the mesometrial triangle raises the question of the function of migrating trophoblast in any species. It cannot be by accident that human trophoblast cells produce the steroidal and other hormones of pregnancy and we may speculate that one of their 
functions is to ensure high local levels of such hormones, but to what purpose? In the suppression of immunological rejection phenomena between the mother and the potentially antigenic trophoblast, local chorionic gonadotrophins may have a rôle to play. The nature of the perivascular cellular infiltrate in the mesometrial triangle at the time of the first trophoblast migration leads us to suspect that immunological reactions, which would require controlling mechanisms, may occur at some stage of pregnancy.

Another possible function for the migrating trophoblast emerges from a comparison of the spiral artery vascular changes in a deciduoma with those in the placental bed. In a deciduoma from Day 13 to term, spontaneous necrosis occurs in retrograde fashion up the central arterial supply but has not reached the medial terminal arteries by parturition unless parturition is artificially delayed by progesterone injections (unpublished observations). In a conceptus, this spontaneous necrosis is not seen though it may occur and be masked by the fibrinoid reaction between the second wave of migrating trophoblast and the vessel wall. In fact, necrosis of the vessel wall may be essential for the subsequent migration of trophoblast. On the other hand, the intraluminal trophoblast in the mesometrial arteries from the first migration is ideally placed to supply hormone secretions through the central blood flow to modify lytic degeneration in the vessel wall.

It is clear that the hamster does offer a good model for the study of haemochorial placentation. The pattern of trophoblast migrations and the way in which they and the vascular changes are so consistently and precisely timed are potentially useful features. The slower development of vascular changes in the walls of the medial terminal arteries compared to the spiral arteries could be helpful in determining whether normal developmental stages are reached at the right time in experimental situations. For example, stromal granulocytes are seen in the walls of the spiral arteries on Day 8 but not until Day 11 in the medial terminal arteries. There is a corresponding delay in the development of such features as stromal sheaths, swelling of medial cells and accumulation of intramural PAS-positive material. This time interval lengthens as the changes extend retrogradely, indicating a gradual slowing down in the second half of pregnancy of what we have called decidualization of the central arterial supply. The same holds true for the onset of necrosis of vessel walls in deciduomata; the necrosis extends retrogradely at diminishing speed and has not reached the medial terminal arteries by the time of parturition.

\section{ACKNOWLEDGMENTS}

This work was supported by grant 20,035 from the Fonds voor Geneeskundig Wetenschappelijk Onderzoek of the Belgian Government. W.R.B. was a Visiting Professor of the University of Leuven, 1972-73.

\section{REFERENGES}

Adams, F. W. \& Hillemann, H. H. (1950) Morphogenesis of the vitelline and allantoic placenta of the golden hamster (Cricetus auratus). Anat. Rec. 108, 363.

Billington, W. D. (1966) Vascular migration of transplanted trophoblast in the golden hamster. Nature, Lond. 211, 988. 
BLoch, S. (1964) Die Glandula myometrialis im Uterus der Maus. Acta anat. 56, 103.

Brosens, I., Robertson, W. B. \& Dixon, H. G. (1967) The physiological response of the vessels of the placental bed to normal pregnancy. 7. Path. Bact. 93, 569.

Dallenbach, F. D. \& Dallenbach-Hellweg, G. (1964) Immunohistologische Untersuchungen zur Lokalisation des Relaxins in menschlicher Plazenta und Dezidua. Virchows Arch. path. Anat. Physiol. 337, 301.

Dallenbach-Hellweg, G., Battista, J. V. \& Dallenbach, F. D. (1965) Immunohistological and histochemical localization of relaxin in the metrial gland of the pregnant rat. Am. F. Anat. 117, 433.

De Wolf, F., De Wolf-Peeters, G. \& Brosens, I. (1973) Ultrastructure of the spiral arteries in the human placental bed at the end of normal pregnancy. Am. 7. Obstet. Gynec. 117, 833.

Droogleever FortuYn, A. B. (1929) Prenatal death in the striped hamster (Cricetulus griseus, M.-Edw.) Archs Biol., Paris, 39, 583.

Graves, A. P. (1945) Development of the golden hamster, Cricetus auratus Waterhouse, during the first nine days. Am. F. Anat. 77, 219.

Hamizron, W. J. \& BoYd, J. D. (1960) Development of the human placenta in the first three months of gestation. F. Anat. 94, 297.

HamperL, H. (1954) Ueber die endometrialen Granulozyten (endometriale Körnchenzellen). Klin. Wschr. 32, 665.

HARris, J. W. S. \& RAMSEY, E. M. (1966) The morphology of human utero-placental vasculature. Contr. Embryol. 38, 43.

Helsweg, G. (1957) Ueber Auftreten und Verhalten der endometrialen Körnchenzellen im Verlauf der Schwangerschaft, im krankhaft veränderten Endometrium und ausserhalb des Corpus uteri. Virchows Arch. path. Anat. Physiol. 330, 658.

Hellweg, G. \& Shaka, J. A. (1959) Endometrial granulocytes. Tissue culture studies of endometrium and decidua with special attention to the endometrial granulocytes. Obstet. Gynec., N.Y. 13, 519.

Jaeger, J. \& Dallenbach-Helweg, G. (1969) Elektronenmikroskopische Befunde an den endometrialen Körnchenzellen des Menschen. Gynaecologia, 168, 117.

Larkin, L. H. \& Schultz, R. L. (1968) Histochemical and autoradiographic studies of the formation of the metrial gland in the pregnant rat. Am. F. Anat. 122, 607 .

LeNDrum, A. G. (1947) The phloxine-tartrazine method as a general histological stain and for the demonstration of inclusion bodies. 7. Path. Bact. 59, 399.

Peach, R. \& Bulmer, D. (1965) Cytochemistry and electron microscopy of the granulated metrial gland cells of the rat placenta. $\mathcal{F}$. Anat. $99,415$.

Robertson, W. B. \& Manning, P. J. (1974) Elastic tissue in uterine blood vessels. F. Path. Bact. (in press).

SeLYe, H. \& MCKeown, T. (1935) Studies on the physiology of the maternal placenta in the rat. Proc. R. Soc. Lond. B, 119, 1.

SMrrH, L. J. (1966) Metrial gland and other glycogen containing cells in the mouse uterus following mating and through implantation of the embryo. Am. J. Anat. 119, 15.

WARD, M. C. (1948) The early development and implantation of the golden hamster, Cricetus auratus, and the associated endometrial changes. Am. F. Anat. 82, 231.

WARD ORsini, M. (1954) The trophoblastic giant-cells and endovascular cells, associated with pregnancy in the hamster, Cricetus auratus. Am. F. Anat. 94, 273.

WARD ORSINI, M. (1957) The vascular knot of the hamster uterus: the placental arterial supply and its changes during gestation and postpartum involution. F. Morph. 100, 565.

WARD ORSINI, M. (1968) Observations on deciduomata in sterile horns of pregnant hamsters. F. Endocr. 41, vii. 